\title{
Zinc May Protect Remote Ocular Injury Caused by Intestinal Ischemia Reperfusion in Rats
}

\author{
GOKHAN OZDEMIR and FATMA INANC ${ }^{1}$ \\ Ophthalmology Department, ' Biochemistry Department, Kahramanmaras \\ Sutcuimam University, Kahramanmaras, Turkey
}

\begin{abstract}
Ozdemir, G. and Inanc, F. Zinc May Protect Remote Ocular Injury Caused by Intestinal Ischemia Reperfusion in Rats. Tohoku J. Exp. Med., 2005, 206 (3), 247-251 Remote organ injury represents the oxidative damage, which occurs in various organs away from the tissues exposed to ischemia-reperfusion insult. Hypothesizing that the eye may be susceptible to this type of tissue damage, we investigated the effect of splanchnic ischemia-reperfusion on the chorio-retinal tissue in Sprague-Dawley rats. Four groups, each consisting of 10 male rats, were designed for the study. Ischemia-reperfusion was introduced by clamping superior mesenteric artery for 1 hour, followed by reperfusion for 90 min (IR group). In another group, the same operation was performed except that zinc aspartate $(50 \mathrm{mg} / \mathrm{kg}$ ) was given intra-peritoneally $15 \mathrm{~min}$ before the opening of the clamp (Zn-IR group). As control (sham group), the abdomen was opened without any intervention on superior mesenteric artery. The other group was given $\mathrm{Zn}$ after opening of abdomen without any intervention on superior mesenteric artery ( $\mathrm{Zn}$-sham group). After the choroid and the retina were dissected from the eye, malondialdehyde, superoxide dismutase, catalase and nitric oxide (NO) were measured in the collected eye tissues. We found that the levels of malondialdehyde, an indicator for lipid peroxidation, were higher in the chorio-retinal tissue of IR group compared to Zn-IR, Zn-sham or sham group $(p<$ $0.05)$. The oxidative stress in Zn-IR group was not higher than that of sham group. Treatment with zinc decreased NO levels but had no noticeable effect on the level of antioxidant enzymes. Our study indicates that remote organ injury is induced in the eye during splanchnic ischemia-reperfusion and that zinc may be beneficial to ameliorate remote ocular injury. - remote ocular injury; zinc; IR injury; chorio-retinal oxidation
\end{abstract}

(C) 2005 Tohoku University Medical Press

The ischemia-reperfusion (IR) injury is seen when the anoxic organ is reperfused by blood supply. IR creates large amount of free oxygen radicals released into the blood circulation and results in generalized inflammatory response and systemic damage (Waisman et al. 2003). Especially reperfusion period generates toxic oxy- gen radicals which have deleterious effect on cellular membranes (Cetinus et al. 2005).

Remote organ injury represents the oxidative stress occurred in various tissues away from the organs exposed to IR insult. It may take place in the organs where vascular network is well-developed (Guler et al. 2004). Several approaches

Received March 23, 2005; revision accepted for publication April 25, 2005.

Correspondence: Dr. Gokhan Ozdemir, KSU Tip Fakultesi, 46050, Kahramanmaras, Turkey.

e-mail: gozdemir@hotmail.com, gozdemir@ksu.edu.tr 
have been suggested to ameliorate both local and distant organ oxidation in IR injury and some antioxidant agents, such as zinc, have been successfully used in experimental animal models (Sakaguchi et al. 2002; Calikoglu et al. 2003; Ozkan et al. 2004). To the best of our knowledge, there have been no reports about the biochemical oxidative changes occurring in the eye associated with intestinal IR. Since the chorio-retinal complex (choroid and retina) has a well developed vascular system, it may be a target for remote organ damage and some preventive approaches may be of benefit. In this study, we investigated the effect of zinc supplementation on remote ocular injury after splanchnic IR.

\section{Materials And Methods}

This study was conducted in Animal Research Laboratory of Medical School of Kahramanmaras Sutcuimam University, after the approval from the institutional ethics committee for animal research was obtained. Forty male Sprague-Dawley rats (weight 250 $-300 \mathrm{~g}$ ) were divided into 4 groups each containing 10 rats. Surgery was conducted under general anesthesia with intra-peritoneal ketamine $(50 \mathrm{mg} / \mathrm{kg}$ ) and xalazine (3 $\mathrm{mg} / \mathrm{kg}$ ). Subcutaneous isotonic saline of $7 \mathrm{cc}$ was given behind the neck to all rats at the beginning of experiment. In one group, the abdomen was opened and superior mesenteric artery (SMA) was found and clamped for 60 min, and then the clamp was released and reperfusion of the splanchnic region was maintained for 90 min (IR group). In another group, the same operation was done but zinc aspartate $(50 \mathrm{mg} / \mathrm{kg})$ was given intra-peritoneally $15 \mathrm{~min}$ before the opening of the clamp (Zn-IR group). The rest of the operation was the same. In control group, only abdomen was opened and SMA was found without clamping and intra-peritoneal saline was given at the 45 th minute after start of experiment (sham group). Another control group took only $\mathrm{Zn} 45$ minutes after opening of the abdomen without any intervention on SMA (Zn-sham group). Intra-peritoneal saline was given at the 45th minute in IR group also. At the end of experiment, all animals were sacrificed with intra-cardiac blood withdrawal. The eyes were enucleated and the retina and choroid were dissected. The chorio-retinal specimens were taken in fifteen minutes and kept at $-20^{\circ} \mathrm{C}$ until biochemical analyses were done.

The right and left eyes were homogenized separate- ly in phosphate buffer and superoxide dismutase (SOD), catalase (CAT), malondialdehyde (MDA), and nitric oxide (NO) were measured in specimens. MDA detection was based on the measurement of the absorbance of thiobarbituric acid-malondialdehyde (Ohkawa et al. 1979). CAT activity was spectrophotometrically measured by the disappearance of $\mathrm{H}_{2} \mathrm{O}_{2}$ at $230 \mathrm{~nm}$ (Beutler 1975). NO was measured with Griess method by the detection of nitrite levels (Cortas and Wakid 1990). SOD activity was determined as described by Fridovich (1974). This method employs xanthine and xanthine oxidase to generate superoxide radicals, which react with 2-(4-iodophenyl)-3-(4-nitro phenol-s-phenyl tetrazolium chloride) to form a red formazan dye. SOD activity is then measured by the degree of inhibition of this reaction. Protein was measured according to Lowry et al. (1951).

For statistical analyses, Kruskal Wallis analysis of variance, Wilcoxon signed rank test and Fisher's exact chi square test were used as appropriate. A probability level of less than 0.05 was chosen as a threshold for statistical significance $(p<0.05)$. All data were shown as mean \pm S.D.

\section{Results}

There was no difference between the groups with regard to operation duration and the amount of the anesthetic drugs used. The right and left eyes showed no noticeable difference with regard to the investigated parameters, and twenty eyes in each group were studied. IR group had almost three times more oxidative stress than IR-Zn group had. MDA level was $86.94 \pm 13.87 \mathrm{nmol} /$ $\mathrm{mg}$ protein and $31.17 \pm 7.11 \mathrm{nmol} / \mathrm{mg}$ protein in IR and Zn-IR groups, respectively $(p<0.05)$ (Table 1). The MDA level was similar between sham and Zn-IR groups $(p<0.05)$. The NO level was lowered in the groups treated with $\mathrm{Zn}(p<$ $0.05)$; it was $0.03 \pm 0.01 \mu \mathrm{mol} / \mathrm{mg}$ protein and 1.07 $\pm 0.35 \mu \mathrm{mol} / \mathrm{mg}$ protein in Zn-IR and IR groups, respectively (Table 1). There was no difference in the NO level between IR and sham group $(p>$ $0.05)$.

Antioxidant enzymes, catalase and superoxide dismutase, were decreased in IR and Zn-IR group compared to sham group (Table 2). With regard to these enzyme activities, there was no difference between IR and Zn-IR groups $(p>$ 
TABLE 1. MDA and NO levels among the groups

\begin{tabular}{ccccc}
\hline & Sham group & Zn-Sham group & IR group & Zn-IR group \\
\hline MDA & $25.30 \pm 6.01$ & $19.98 \pm 7.08$ & $86.94 \pm 13.87^{*} \dagger$ & $31.17 \pm 7.11$ \\
$(\mathrm{nmol} / \mathrm{mg}$ protein $)$ & $(9.03-38.20)$ & $(13.60-40.00)$ & $(38.61-166.03)$ & $(15.70-62.55)$ \\
NO & $0.88 \pm 0.21$ & $0.02 \pm 0.01^{*}$ & $1.07 \pm 0.35 \dagger$ & $0.03 \pm 0.01^{*}$ \\
$(\mu \mathrm{mol} / \mathrm{mg}$ protein $)$ & $(0.10-1.33)$ & $(0.01-0.09)$ & $(0.06-3.07)$ & $(0.01-0.13)$ \\
\hline
\end{tabular}

Data are given as mean \pm S.D. and the range (in brackets).

MDA, malondialdehyde (nmol/mg protein); NO, nitric oxide ( $\mu \mathrm{mol} / \mathrm{mg}$ protein).

* Significant compared to sham group (Kruskal Wallis analysis of variance, $p<0.05$ )

$\dagger$ Significant compared to Zn-IR and Zn-sham groups.

TABLE 2. Catalase and SOD levels among the groups

\begin{tabular}{|c|c|c|c|c|}
\hline & Sham group & Zn-Sham group & IR group & Zn-IR group \\
\hline $\begin{array}{c}\mathrm{CAT} \\
\left(\begin{array}{c}\mathrm{U} / \mathrm{mg} \\
\text { protein }\end{array}\right)\end{array}$ & $\begin{array}{r}1108.03 \times 10^{4} \pm 216.10 \times 10^{4} \\
\left(128.77 \times 10^{4}-2244.18 \times 10^{4}\right)\end{array}$ & $\begin{array}{c}1274.66 \times 10^{4} \pm 185.77 \times 10^{4} \\
\left(309.83 \times 10^{4}-2817 \times 10^{4}\right)\end{array}$ & $\begin{array}{c}202.33 \times 10^{4} \pm 57.14 \times 10^{4 *} \neq \\
\left(\text { nil }-405.23 \times 10^{4}\right)\end{array}$ & $\begin{array}{c}371.46 \times 10^{4} \pm 89.22 \times 10^{4 *} \\
\left(\text { nil }-660.80 \times 10^{4}\right)\end{array}$ \\
\hline $\begin{array}{c}\mathrm{SOD} \\
\left(\begin{array}{c}\mathrm{U} / \mathrm{mg} \\
\text { protein }\end{array}\right)\end{array}$ & $\begin{array}{l}448.51 \pm 105.48 \\
(65.70-876.04)\end{array}$ & $\begin{array}{l}409.96 \pm 87.85 \\
(56.20-715.27)\end{array}$ & $\begin{array}{c}183.65 \pm 34.76^{*} \ddagger \\
(49.47-313.71)\end{array}$ & $\begin{array}{l}173.65 \pm 33.04^{*} \\
(86.10-211.10)\end{array}$ \\
\hline
\end{tabular}

Data are given as mean \pm S.D. and the range (in brackets).

SOD, superoxide dismutase (unit/mg protein); CAT, catalase (unit/mg protein).

${ }^{*}$ significant compared to sham and $\mathrm{Zn}$-sham group (Kruskal Wallis analysis of variance, $p<0.05$ ).

$\$$ not significant compared to Zn-IR group.

0.05). There was no difference between two sham groups in which the enzyme levels were high $(p>$ $0.05)$.

\section{Discussion}

Ischemia-reperfusion injury is caused by the increased oxygen supply after a period of ischemia, leading to excess formation of hydroxyl and lipid radicals (Calikoglu et al. 2003; Waisman et al. 2003). Multiple organ damage after ischemia reperfusion injury has been called as remote organ injury (Nielsen et al. 1997; Guler et al. 2004; Okutan et al. 2004).

Splanchnic ischemia may be caused by several mechanisms, such as emboli or thrombosis of SMA, or when mesenteric clamps were put during bowel surgery, and the resultant cellular hypoxia activates a variety of vascular and inflammatory mediator systems. Although the reinstitution of blood flow to ischemic tissues is critical to their salvage, the reperfusion of ischemic organs may paradoxically increase the tissue damage induced by the ischemia (Waisman et al. 2003), causing local and systemic destruction. Remote organs with intense micro-capillary systems such as lung and kidney are prone to develop this type of systemic injury (Calikoglu et al. 2003; Guler et al. 2004).

We showed intestinal ischemia reperfusion induced biochemical oxidative stress in the chorio-retinal part of the eye, as indicated by high MDA levels. The ischemic activation of leukocytes is mostly accepted mechanism to explain the basis of this distant injury (Paterson et al. 1989; Calikoglu et al. 2003; Okutan et al. 2004). Leukocytes exposed to ischemic tissue may reenter the systemic circulation in an activated state upon reperfusion and have been implicated as 
mediators of remote organ injury. After adhering to endothelium, leukocytes transmigrate across endothelial surfaces into the tissues and exert their toxic effects through the release of proteolytic enzymes and free radicals, resulting in micro-vascular dysfunction and local inflammatory response (Waisman et al. 2003). MDA is, in particular, produced by lipid peroxidation and serves as an index of biochemical oxidative damage in the tissue (Gul et al. 2005). It can reliably be used to investigate the degree of tissue damage. We found that $\mathrm{Zn}$-IR and sham groups had equal MDA levels, whereas IR group had the highest biochemical oxidative stress. The lipid peroxidation in IR group is almost twice that of sham group and higher than that of Zn-IR group, implying the chorio-retinal tissue is injured after IR attack of intestines. We confirmed the beneficial action of $\mathrm{Zn}$ against oxidative changes.

Studies in cell culture and animal models have shown that zinc serves as an antioxidant, possibly arising from two mechanisms. First, it spares redox-active metals, and second, it can induce antioxidant protein metallothionein which can scavenge hydroxyl radicals (Tate et al. 1999; Prasad et al. 2004). Some investigators called attention that zinc may exert tissue protective effects independent from its anti-oxidative properties, which may arise from DNA binding capability or the inhibition of calcium influx (Waring et al. 1990).

In our study zinc had an inhibitory effect on NO synthesis, which is suggested as one of its anti-oxidative mechanisms (Prasad et al. 2004). It is reported that increased tissue damage and nitric oxide are associated with the decreased levels of $\mathrm{Zn}$ and SOD activity (Rajesh et al. 2003). Zinc interacts with cytokines to inhibit nitric oxide production and lowers oxidative stress byproducts (Prasad et al. 2004). Free radicals may create peroxynitrite when NO is found in the medium and exacerbate oxidative damage in addition to direct actions of oxygen radicals (Asahi et al. 1995). We confirmed that $\mathrm{Zn}$ decreased NO profoundly, which may be related to our finding of low MDA in Zn-IR group, although some mechanisms other than NO pathway may work. Several authors, on the contrary, claim that NO may have some tissue protective and anti-inflammatory aspects (Miralles et al. 2000; Waisman et al. 2003). When peroxynitrite is formed, NO works as an oxidizing agent.

As a consequence of ongoing intestinal injury, chorio-retinal enzymes were depleted in our experiment, exposing eye to oxidative damage. Although we could not confirm, it has been reported that $\mathrm{Zn}$ deficient rats have diminished SOD activity and longevity (Rajesh et al. 2003) and increased zinc supplementation is associated with higher SOD activity (Mates et al. 1999).

We have shown that remote ocular injury may develop following intestinal ischemia reperfusion, which may be ameliorated by $\mathrm{Zn}$ supplementation. To our knowledge this is the first study showing the remote oxidative stress in the eye. Another issue to be studied is which part of the eye is the target, choroid or retina. The clinical significance of our study must be confirmed in abdominal surgery patients on the basis of involvement of the chorio-retinal tissue.

\section{References}

Asahi, M., Fujii, J., Suzuki, K., Seo, H.G., Kuzuya, T., Hori, M., Tada, M., Fujii, S. \& Taniguchi, N. (1995) Inactivation of glutathione peroxidase by nitric oxide. J. Biol. Chem., 270, 21035-21039.

Beutler, E. (1975) Red Cell Metabolism, 2nd ed., Grune and Stratton Company, New York, pp. 261-265.

Calikoglu, M., Tamer, L., Sucu, N., Coskun, B., Ercan, B., Gul, A., Calikoglu, I. \& Kanik, A. (2003) The effects of caffeic acid phenethyl ester on tissue damage in lung after hindlimb ischemia-reperfusion. Pharmacol. Res., 48, 397-403.

Cetinus, E., Kilinc, M., Inanc, F., Kurutas, E.B. \& Buzkan, N. (2005) The role of urtica dioica (urticaceae) in the prevention of oxidative stress caused by tourniquet application in rats. Tohoku J. Exp. Med., 205, 215-221.

Cortas, N.K. \& Wakid, N.W. (1990) Determination of inorganic nitrate in serum and urine by akinetic cadmium reduction method. Clin. Chem., 36, 1440-1443.

Fridovich, I. (1974) Superoxide dismutase. Adv. Enzymol., 41, 35-97.

Gul, M., Kurutas, E., Ciragil, P., Cetinkaya, A., Kilinc, M., Aral, M. \& Buyukbese, M.A. (2005) Urinary tract infection aggravates oxidative stress in diabetic patients. Tohoku J. Exp. Med., 206, 1-6.

Guler, C., Samli, M., Aksoy, Y., Demirbas, M., Kilinc, A., Ellidokuz, E. \& Dincel, C. (2004) Effects of carbon dioxide pneumoretroperitoneum on free radical formation in remote organs and use of verapamil as an antioxidant. J. Endourol., 18, 245-249.

Lowry, O.H., Rosebrough, N.J., Farr, A. \& Randall, R. (1951) 
Protein measurement with the folin phenol reagent. J. Biol. Chem., 193, 265-275.

Mates, J.M., Perez-Gomez, C. \& De Castro, I.N. (1999) Antioxidant enzymes and human diseases. Clin. Biochem., 32, 595-603.

Miralles, C., Busquets, X., Santos, C., Togores, B., Hussain, S., Rahman, I., MacNee, W. \& Agusti, A.G. (2000) Regulation of iNOS expression and glutathione levels in rat liver by oxygen tension. FEBS Lett., 476, 253-257.

Nielsen, V.G., Tan, S., Baird, M.S., Samuelson, P.N., McCammon, A.T. \& Parks, D.A. (1997) Xanthine oxidase mediates myocardial injury after hepatoenteric ischemia perfusion. Crit. Care Med., 25, 1044-1050.

Ohkawa, H., Ohishi, N. \& Yagi, K. (1979) Assay for lipid peroxides in animal tissues by thiobarbituric acid reaction. Ann. Biochem., 95, 351-358.

Okutan, H., Savas, C., Ozguner, F., Yonden, Z., Eren, V.C. \& Delibas, N. (2004) Lung injury after aortic occlusion-reperfusion in rats: the role of gadolinium chloride. Tohoku J. Exp. Med., 203, 267-273.

Ozkan, K.U., Boran, C., Kilinc, M., Garipardic, M. \& Kurutas, E.B. (2004) The effect of zinc aspartate pretreatment on ischemia-reperfusion injury and early changes of blood and tissue antioxidant enzyme activities after unilateral testicular torsion-detorsion. J. Pediatr. Surg., 39, 91-95.

Paterson, I.S., Klausner, J.M., Pugatch, R., Allen, P., Mannick, J.A. \& Shepro, D. (1989) Noncardiogenic pulmonary ede- ma after abdominal aortic aneurysm surgery. Ann. Surg., 209, 231-236.

Prasad, A.S., Bao, B., Beck, F.W.J., Kucuk, O. \& Sarkar, F.H. (2004) Antioxidant effect of zinc in humans. Free Rad. Biol. Med., 37, 1182-1190.

Rajesh, M., Sulochana, K.N., Punitham, R., Biswas, J., Lakshmi, S. \& Ramakrishnan, S. (2003) Involvement of oxidative and nitrosative stress in promoting retinal vasculitis in patients with Eales' disease. Clin. Biochem., 36, 377-385.

Sakaguchi, S., Iizuka, Y., Furusawa, S., Ishikawa, M., Satoh, S. \& Takayanagi, M. (2002) Role of $\mathrm{Zn} 2+$ in oxidative stress caused by endotoxin challenge. Eur. J. Pharmacol., 451, 309-316.

Tate, D.J., Miceli, M.V. \& Newsome, D.A. (1999) Zinc protects against oxidative damage in cultured human retinal pigment epithelial cells. Free Rad. Biol. Med., 26, 704-713.

Waisman, D., Brod, V., Wolff, R., Sabo, E., Chernin, M., Weintraub, Z., Rotschild, A. \& Bitterman, H. (2003) Effects of hyperoxia on local and remote microcirculatory inflammatory response after splanchnic ischemia and reperfusion. Am. J. Physiol. Heart Circ. Physiol., 285, H643-H652.

Waring, P., Egan, M., Braithwaite, A., Mullbacher, A. \& Sjaarda, A. (1990) Apoptosis induced in macrophages and $\mathrm{T}$ blasts by the mycotoxin sporidesmin and protection by $\mathrm{Zn}$ salts. Int. J. Immunopharmac., 12, 445-457. 